\title{
HOW READY ARE CUSTOMERS TO RE-TRAVEL FOR TOURISM? INSIGHTS FROM THE UAE AND EGYPT
}

\begin{abstract}
Mohamed ABOU-SHOUK*
University of Sharjah, College of Arts, Humanities and Social Sciences, Department of History and Islamic Civilization, Sharjah, UAE; Fayoum University, Faculty of Tourism and Hotels, Department of Tourism Studies, Fayoum, Egypt, e-mail: maboushouk@sharjah.ac.ae

Nagoua ZOAIR

Fayoum University, Fayoum, Faculty of Tourism and Hotels, Department of Tourism Guidance, Egypt, e-mail: nia00@ fayoum.edu.eg

\section{Emadeddin ABULENEIN}

University of Sharjah, College of Arts, Humanities and Social Sciences,

Department of History and Islamic Civilization, Sharjah, UAE e-mail: eabuelenain@ sharjah.ac.ae

Citation: Abou-Shouk, M., Zoair, N., \& Abulenein, E. (2022). HOW READY ARE CUSTOMERS TO RE-TRAVEL FOR TOURISM? INSIGHTS FROM THE UAE AND EGYPT. GeoJournal of Tourism and Geosites, 40(1), 175-180. https://doi.org/10.30892/gtg.40121-817

Abstract: This study aims to investigate individuals' perceptions of travel fear and anxiety of COVID-19, the protection procedures taken by both UAE and Egypt to maintain tourists' safety and how these perceptions affect travel intentions. An online questionnaire is implemented to collect data from a convenient sample of the UAE and Egypt populations and structural equation modelling was employed for analysis purposes. Findings show that the intention of travel varies according to individuals' belief in the protection measures across the UAE and Egypt.
\end{abstract}

Key words: Travel Fear and Anxiety, Travel Intention, Protection Procedures, UAE, Egypt

\section{INTRODUCTION}

Since the World Health Organization declared COVID-19 as a pandemic in 2020, the biggest global lockdown has taken place with an emphasis on international travel for tourism (Turnšek et al., 2020). Thus, tourism has experienced its worst in the year of 2020 in history with a decrease reached $74 \%$ in international arrivals with an expectation to rebound to normal levels in 2023 (UNWTO, 2021). According to the expectations of Škare et al., (2021), the recovery of travel and tourism will take more than the expected average of ten months. According to UNWTO experts, it will take from 2.5 to 4 years to recover to 2019 levels of international tourist flow. Some experts would rather expect a significant increase during 2022. As for 2024 or later, they also expect some return to pre-pandemic levels. Experts expect that the change would be rabid in the Middle East while it could be slower but more stable in Europe, the Americas, Asia and the Pacific, and Africa (UNWTO, 2021). With the rollout of COVID-19 vaccines and careful travel precautions taken by tourist destinations, it is expected that tourists will become gradually and slowly confident to restart their travel for tourism (UNWTO, 2021). The present study aims to explore the causal relationship between travel fear and anxiety and intention to travel considering the moderating role of protection measures' efficacy based on collected data from the UAE and Egypt.

\section{LITERATURE REVIEW}

\section{Travel Fear}

Emotions were a centre of interest in tourism research due to their impact on tourists' cognitive evaluations and behavioural responses (Cohen and Cohen, 2012; Volo, 2021). The definition of emotion is multifaceted and varies according to the domain of science, but it is agreed that it is difficult to be observed. It is a complex phenomenon that includes joy, sadness, fear and anger. Fear is defined as a natural emotion that is exposed in case of danger, pain, or harm (Luo and Lam, 2020). Travel activities evoke many aspects of fear or phobia like agoraphobia (vast public spaces), aviophobia (air travel), and nosophobia (infectious disease) (Zenker et al., 2021). After the declaration of COVID-19 as a pandemic, fear arises among populations of the world, which figures the attention of scholars in different disciplines. Ahorsu et al., (2020) established the "Fear of COVID-19 Scale (FCV-19)" to identify the level of fear among the population. This could include the fear of losing life, and to be infected and so on. Previous studies have attempted to measure the level of fear among populations (i.e., Bratić et al., 2021; Luo and Lam, 2020, Magano et al., 2021; Wachyuni and Kusumaningrum, 2020). Turnšek et al. (2020) tested the effect of pandemic's severity and susceptibility on travel avoidance decisions and found that gender, experience, and age have been significantly associated with travel avoidance decisions. Similarly, Zheng et al., (2021) found that fear of COVID-19 is a substantial predictor of travel avoidance decisions. Hence, the first hypothesis is developed as follows:

H1: Travel fear has a negative effect on travel intention.

\footnotetext{
${ }^{*}$ Corresponding author
} 


\section{Travel Anxiety}

Anxiety is a disorder mental state that has cognitive, emotional, and behavioural dimensions (Zenker et al., 2021). It includes feelings of tension and worries about the future, potential risk, or actual risk (Luo and Lam, 2020; Reisinger and Mavondo, 2005), being uncomfortable, nervous, stressed, unbalanced, or frustrated (Hullett and Witte, 2001; McIntyre and Roggenbuck, 1988). Travel decision involves a complex process of cognitive feelings, emotions, and risks that may recall a state of anxiety in case of threats which is negatively associated with the travel intention (Reisinger and Mavondo, 2005). In tourism, researchers explored the effect of anxiety on travel behavioural intention in different countries. Recently, Zenker et al. (2021) developed a scale for anxiety and found that anxiety is negatively influencing intentions. This finding was previously confirmed by Reisinger and Mavondo (2005) revealing that anxiety has a negative impact on travel intention. Likewise, Luo and Lam (2020), Wachyuni and Kusumaningrum (2020), Magano et al. (2021), and Bratić et al. (2021) found similar results of the negative effect of anxiety on travel intention and behaviour. Therefore, the second hypothesis is developed as follows:

H2: Travel anxiety is negatively affecting travel intention.

\section{Fear and Anxiety}

The two terms of fear and anxiety are overlapped but they are different. The most obvious distinction is that fear is an awareness of actual danger while anxiety is a response to anticipated threat (Luo and Lam, 2020). Fear happens because of a particular reason while anxiety does not require a certain motivation (Perusini and Fanselow, 2015). Although literature studies have revealed a significant effect of fear and anxiety of COVID-19 on travel intentions, some studies depicted that this fear is an antecedent to anxiety (i.e., Luo and Lam, 2020; Rodríguez-Hidalgo et al., 2020). On the destinations' level, Joo et al. (2021) found that the perceived risk of receiving tourists by destinations would negatively affect residents' support for tourism. Thus, the third hypothesis is initiated as follows:

H3: Travel fear has a positive impact on travel anxiety.

\section{Protection Measures}

Predeparture health measures could be more helpful to ensure safety and prevent the additional creation of job losses and commercial collapse. Some countries have introduced the use of vaccine passports as a means of ensuring safe tourist travel. Countries started to encourage tourist flow with new "safe and clean labels" for the tourism industry, news apps for tourists and local tourism marketing campaigns. They began to use innovative "health protocols" for secure tourism and assist to vary their potential customers (OECD, 2020). Countries have also started to initiate "border processes \& procedures". They were keen to guarantee provincial and worldwide direction in the re-launching of frontiers for travel. Countries were eager on improving the utilization of technology for contactless tourism. They also try to guarantee the management of appropriate procedures and actions among travel, health, internal and transportation agencies. One of the examples of such measures that ensure safety is visitors' tracing apps. And the vast usage of "e-visa/visa on arrival/ no visa policies" and short-term visa fee release to promote destinations for more potential tourists. Hotels and resorts launched hitech techniques like "guest messaging" for human contact with guests for bookings, compensations, or cancellations. They introduced new services like home delivery or takeaway service, family accommodation, and "drive \& stay" bundles. Travel agencies enabled international-voucher redeeming for tour packages and services, especially with late cancellations. Countries used alternative tours based on nature such as rural and eco-tourism destinations, sports tours heritage sites, "bird-watching" tours in addition to cultural tours (UNWTO, 2020). Countries take significant precautions to decrease the probability of COVID-19 spread starting from PCR tests for travel and ending with strict social distance, facemasks, and quarantine procedures. With the hope of the produced vaccines' role in limiting infections, both tourists and destinations hope that the tourism restarting process starts soon. A recent study by Zheng et al. (2021) tested the perceptions of travellers' selfefficacy and response efficacy and found that these perceptions significantly influence travellers' motivation protection which in turn affects cautious travel intention decisions. Response efficacy refers to the adequacy and significance of measures taken by destinations for safe travel of tourists which is referred to as 'protection measures' efficacy' in the present study. The present study hypothesizes that the protection measures efficacy would decrease the effect of travel fear and anxiety on travel intention if seriously and strictly applied. Therefore, the fourth proposition of the present study is formulated as follows:

H4: Protection measures' efficacy negatively moderates the relationship between travel fear, travel anxiety and travel intention.

\section{RESEARCH MODEL}

Based on the literature review on the relationship between fear of travel and travel intention (i.e., Turnšek et al., 2020; Zheng et al., 2021), and the effect of travel anxiety on travel intention (i.e., Luo and Lam, 2020; Reisinger and Mavondo, 2005, Zenker et al., 2021), the relationship between fear and anxiety (i.e., Luo and Lam, 2020; Reisinger and Mavondo, 2005), and the effect of measures efficacy on travel intention (Zheng et al., 2021), the research model is developed (Figure 1).

Four research propositions were developed as follows:

H1: Travel fear has a negative effect on travel intention.

H2: Travel anxiety is negatively affecting travel intention.

H3: Travel fear has a positive impact on travel anxiety.

H4: Protection measures' efficacy negatively moderates the relationship between travel fear, travel anxiety and travel intention.

\section{RESEARCH METHODS}

The present study adopts the quantitative method based on an e-survey to collect data from respondents in the UAE and Egypt. The sample framework of the study is the population of the UAE and Egypt. However, the study used a convenient 
sample to collect data due to the effects of COVID-19. The survey was prepared in English and Arabic and was sent to respondents using emails and social media to reach a wide range of populations. Data were collected between February and March 2021. Structural equation modelling was utilized to test research hypotheses. 421 forms were collected from the UAE compared to 410 from Egypt. The questionnaire form included the demographic data of respondents (gender, age, and qualification), in addition to questions about their travel purpose (i.e., for tourism or other purposes) and if they travel internationally or locally. 15 statements were developed based on literature studies to measure the main four constructs of the research model using the five-point Likert scale (agree-disagree). Four statements were used to measure travel fear based on the research of Ahorsu et al. (2020) and Luo and Lam (2020). Three statements were used to measure travel anxiety based on studies by Zenker et al. (2021) and Luo and Lam (2020). Four statements were employed to measure the protection measures efficacy based on literature studies of Zheng et al. (2021). Three statements were adapted to measure travel intention based on research of Reisinger and Mavondo (2005), Lee et al. (2012), Abou-Shouk et al. (2019), and Soliman and Abou-Shouk (2017). Data analyses were limited to respondents who travel regularly for tourism and those who travel internationally only. Profile of respondents, mean values of respondents' perceptions, statistical differences among countries and gender using t-test, and measurement models' validity and reliability are presented in tables 1 to 3 .

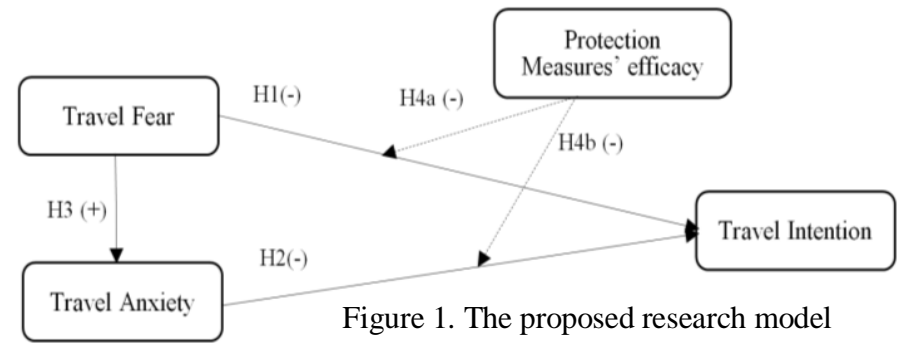

\section{FINDINGS AND ANALYSIS}

\section{Profile of Respondents}

421 and 410 forms were collected from the UAE and Egypt,

Table 1. Profile of respondents

\begin{tabular}{|c|l|c|c|c|c|}
\hline \multicolumn{2}{|c|}{} & \multicolumn{2}{c|}{ UAE (300) } & \multicolumn{2}{c|}{ Egypt (260) } \\
\cline { 3 - 6 } \multicolumn{2}{|c|}{} & Frequency & $\%$ & Frequency & $\%$ \\
\hline \multirow{3}{*}{ Gender } & Male & 91 & 29.5 & 150 & $57.8 \%$ \\
\cline { 2 - 6 } & Female & 219 & 70.5 & 110 & $42.2 \%$ \\
\hline \multirow{4}{*}{ Age } & $18-25$ & 125 & 40.3 & 30 & $11.7 \%$ \\
\cline { 2 - 6 } & $26-35$ & 82 & 26.4 & 103 & $39.5 \%$ \\
\cline { 2 - 6 } & $36-45$ & 69 & 22.3 & 91 & $35.1 \%$ \\
\cline { 2 - 6 } & $46-55$ & 32 & 10.3 & 24 & $9.3 \%$ \\
\cline { 2 - 6 } & $>55$ & 2 & 0.7 & 11 & $4.4 \%$ \\
\hline \multirow{3}{*}{$\begin{array}{l}\text { Qualifi- } \\
\text { cation }\end{array}$} & Secondary & 95 & 30.7 & 44 & $17.0 \%$ \\
\cline { 2 - 6 } & University & 196 & 63.1 & 143 & $54.9 \%$ \\
\cline { 2 - 6 } & Postgraduate & 17 & 5.5 & 67 & $25.7 \%$ \\
\cline { 2 - 6 } & Other & 2 & 0.7 & 6 & $2.4 \%$ \\
\hline
\end{tabular}
respectively. Two criteria were used to filter responses for data analysis purposes. The first is to include respondents who travel regularly for tourism purposes (which is 345 out of 421 responses for the UAE and 300 out of 410 responses for Egypt). Second, data analysis was limited to international travel for tourism (which is 300 responses for the UAE and 260 responses for Egypt). Table (1) shows to demographics of respondents. Females form the majority of the UAE's respondents while males form most of Egypt's respondents. Most respondents are aged between 18 and 25 years in the UAE while the major age category for Egypt's respondents is 26 and 35 years. The university qualification represents most of the respondents' education levels in the UAE and Egypt. To measure the moderation effect, the protective measures have been classified based on the respondents' perceptions to three categories using the mean values: respondents with high perceptions on protective measures (highly adequate and efficient- 120 responses for the UAE and 130 for Egypt), respondents with moderate perceptions (measures are adequate and efficient - 100 responses for the UAE and 110 for Egypt), and respondents with low perceptions (measures are not adequate or efficient - 80 for the UAE and 20 for Egypt). Table (2) depicts the mean values of the research model. Table (2) shows that both the UAE's and Egypt's respondents have neutral

Table 2. Mean values and statistical differences among research model constructs

Note: Significance (sig.) is calculated based on independent samples t-test

\begin{tabular}{|l|c|c|c|c|}
\hline & UAE (mean) & Egypt (mean) & Sig. (country) & Sig. (gender) \\
\hline Fear of travel & 3.2 & 2.7 & $<0.01$ & $<0.01$ \\
\hline Anxiety & 3.0 & 2.5 & $<0.01$ & $<0.01$ \\
\hline $\begin{array}{l}\text { Protection } \\
\text { measures }\end{array}$ & 3.3 & 3.4 & $>0.05$ & $>0.05$ \\
\hline Travel intention & 3.3 & 3.8 & $<0.01$ & $<0.01$ \\
\hline
\end{tabular}

intention. However, it does not affect respondents' perceptions of protection measures.

\section{Measurement Models}

Table (3) displays the validity and reliability of the used scale for the UAE and Egypt. the values of average variance extracted (AVEs) exceed the cut-off value of 0.5 and convergent validity is evident (Hair et al., 2020). The square roots of AVEs exceeded the correlations among constructs, the HTMT ratio show values less than 0.85 and therefore discriminant validity exists (Henseler et al., 2015; Kock, 2020). Hence, the measurement models are valid and reliable.

\section{Structural Models}

Figure (2) illustrates that the travel fear because of COVID-19 is negatively affecting travel intention for the respondents of both countries $\left(\beta_{1}=-0.45, \mathrm{P}<0.01\right.$ for the UAE, $\beta_{2}=-0.27, \mathrm{P}<0.01$ for Egypt, and the first hypothesis is supported). Furthermore, travel anxiety has a negative effect on the travel intention of respondents $\left(\beta_{1}=-0.31\right.$, P<0.01 for the UAE, $\beta_{2}=-0.26, \mathrm{P}<0.01$ for Egypt, and the second hypothesis is supported). The fear of travel has a positive effect on travel anxiety $\left(\beta_{1}=0.68, \mathrm{P}<0.01\right.$ for the UAE, $\beta_{2}=0.27, \mathrm{P}<0.01$ for Egypt, and the third hypothesis is supported). 
Additionally, the protection measures are significantly and negatively affecting the relationship, as a moderator, between travel fear, travel anxiety and travel intention $\left(\beta_{\text {fear-intention }}=-0.11, \mathrm{P}<0.05\right.$ for the UAE, $\beta_{\text {fear-intention }}=-0.15, \mathrm{P}<0.05$ for Egypt, $\beta_{\text {anxiety-intention }}=-0.31, \mathrm{P}<0.01$ for the UAE, $\beta_{\text {anxiety-intention }}=-0.26, \mathrm{P}<0.01$ and the fourth hypothesis is supported). Travel fear, travel anxiety and the moderation of protection measures explain $50 \%$ of the variance in travel intention for the UAE respondents $\left(\mathrm{R}_{1}{ }^{2}=0.50\right)$ and $30 \%$ for the Egyptian respondents $\left(\mathrm{R}_{2}{ }^{2}=0.30\right)$. These findings mean that the respondents of both the UAE and Egypt are afraid and anxious to travel during the pandemic and fear and anxiety have a negative impact on their travel intention. However, respondents showed interest in the protection measures taken by destinations as these protection measures help decrease the influence of fear and anxiety on their intention to travel in the UAE and Egypt.

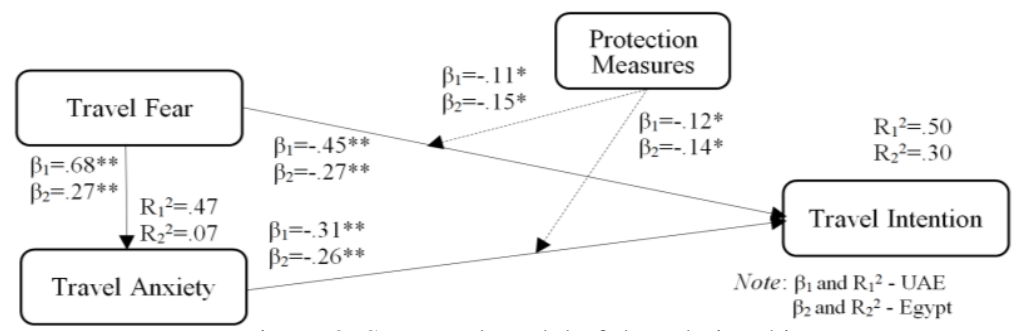

Figure 2. Structural model of the relationship

between travel fear, anxiety, and travel intention

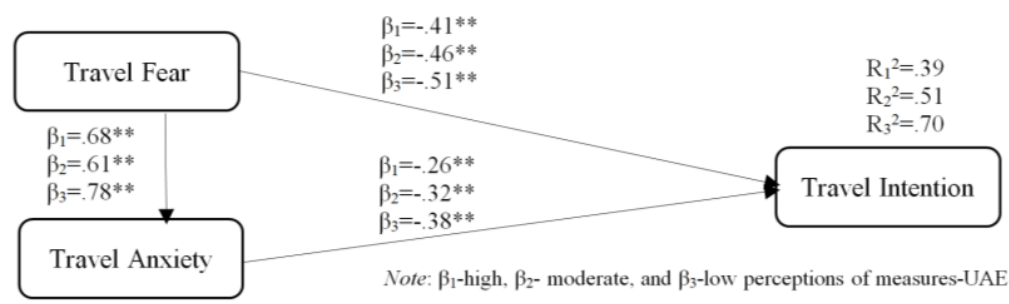

Figure 3. Perceptions of travel protection measures and travel intention for the UAE

To investigate the role of protection measures, each category of respondents (high perceptions inadequacy and efficacy of protection measures, moderate perceptions, and low-perceptions respondents) has been investigated separately to check how this perception of protection measures affect the travel intention of each category. Figure (3) depicts the effect of travel fear and travel anxiety on travel intentions for the UAE respondents. For respondents with high perceptions of protection measures, $39 \%$ of the variance in travel intention is explained by travel fear $\left(\beta_{1}=-0.41, \quad \mathrm{P}<0.01\right)$ and travel anxiety $\left(\beta_{1}=-0.26, P<0.01\right)$. However, for the respondents with moderate perceptions of protection measures, $51 \%$ of the variance in travel intention is explained by travel fear $\left(\beta_{2}=-0.46, P<0.01\right)$ and travel anxiety $\left(\beta_{2}=\right.$ $0.26, \mathrm{P}<0.01)$. In addition, of the respondents with low perceptions of protection measures,

$70 \%$ of the variance in their travel intention is explained by travel fear $\left(\beta_{3}=-0.51, \mathrm{P}<0.01\right)$ and travel anxiety $\left(\beta_{3}=-0.38\right.$, $\mathrm{P}<0.01)$. This means that respondents who believe highly in protection measures, their travel intention is less affected by fear of travel and travel anxiety $\left(\mathrm{R}^{2}=39 \%\right)$ than respondents with moderate perceptions $\left(\mathrm{R}^{2}=51 \%\right)$ and those with low perceptions $\left(\mathrm{R}^{2}=70 \%\right)$. This finding represents the importance of protection measures taken by destinations for safe travel.

Table 3. Validity and reliability of the measurement model for the UAE and Egypt (Note: CA: Cronbach's alpha, CR: Composite reliability)

\begin{tabular}{|c|c|c|c|c|c|c|c|c|c|c|}
\hline \multirow{2}{*}{ Constructs and indicators } & \multicolumn{5}{|c|}{$\mathrm{UAE}$} & \multicolumn{5}{|c|}{ Egypt } \\
\hline & Loading & CA & $\mathrm{CR}$ & AVE & $\sqrt{\mathrm{AVE}}$ & Loading & CA & $\mathrm{CR}$ & AVE & $\sqrt{\mathrm{AVE}}$ \\
\hline \multicolumn{11}{|l|}{ Travel Fear of Covid-19 } \\
\hline I am afraid of COVID-19. & 0.940 & \multirow{4}{*}{0.948} & \multirow{4}{*}{0.963} & \multirow{4}{*}{0.866} & \multirow{4}{*}{0.931} & 0.908 & \multirow{4}{*}{0.917} & \multirow{4}{*}{0.941} & \multirow{4}{*}{0.801} & \multirow{4}{*}{0.895} \\
\hline I am afraid of losing my life because of COVID-19 & 0.895 & & & & & 0.893 & & & & \\
\hline It makes me uncomfortable to think about COVID-19 & 0.941 & & & & & 0.854 & & & & \\
\hline When I check out news about COVID-19 I become afraid to travel & 0.945 & & & & & 0.923 & & & & \\
\hline \multicolumn{11}{|l|}{ Travel Anxiety } \\
\hline COVID-19 makes me worry a lot about my traditional travelling. & 0.915 & \multirow{3}{*}{0.935} & \multirow{3}{*}{0.958} & \multirow{3}{*}{0.885} & \multirow{3}{*}{0.941} & 0.891 & \multirow{3}{*}{0.898} & \multirow{3}{*}{0.936} & \multirow{3}{*}{0.830} & \multirow{3}{*}{0.911} \\
\hline It makes me anxious to think about travel during COVID-19 & 0.958 & & & & & 0.919 & & & & \\
\hline I feel stressed when I think about travel during COVID-19 & 0.948 & & & & & 0.924 & & & & \\
\hline \multicolumn{11}{|l|}{ Protection measures efficacy $(P R)$} \\
\hline $\begin{array}{l}\text { Efforts taken by destinations for health safety during travel } \\
\text { are effective }\end{array}$ & 0.908 & \multirow{4}{*}{0.925} & \multirow{4}{*}{0.947} & \multirow{4}{*}{0.816} & \multirow{4}{*}{0.903} & 0.725 & \multirow{4}{*}{0.783} & \multirow{4}{*}{0.809} & \multirow{4}{*}{0.618} & \multirow{4}{*}{0.786} \\
\hline Preventive measures to decrease COVID-19 infection are adequate & 0.912 & & & & & 0.813 & & & & \\
\hline $\begin{array}{l}\text { It is less likely to expose to COVID-19 threat if I respect the } \\
\text { measures }\end{array}$ & 0.901 & & & & & 0.752 & & & & \\
\hline $\begin{array}{l}\text { If vaccinated against COVID, it is less likely to be infected } \\
\text { during travel }\end{array}$ & 0.892 & & & & & 0.766 & & & & \\
\hline \multicolumn{11}{|l|}{ Travel intention } \\
\hline I intend to travel for tourism in 2021 & 0.962 & \multirow{3}{*}{0.958} & \multirow{3}{*}{0.972} & \multirow{3}{*}{0.922} & & 0.945 & & & & \\
\hline Whenever I have a chance to travel in 2021 , I will & 0.957 & & & & 0.960 & 0.931 & 0.934 & 0.958 & 0.884 & 0.940 \\
\hline I plan to travel in 2021 & 0.960 & & & & & 0.940 & & & & \\
\hline
\end{tabular}

Moving to Egypt's respondents, two categories have been compared (respondents with high and moderate perceptions of protection measures) while the third category is excluded from analysis because of sample inadequacy (20 responses only). Figure (4) shows that travel intention is also affected negatively by travel fear and travel anxiety. It is obvious that $29 \%$ of the variance in travel intention is explained by travel fear $\left(\beta_{1}=-0.44, \mathrm{P}<0.01\right)$ and travel anxiety $\left(\beta_{1}=-0.20, \mathrm{P}<0.05\right)$ for respondents with high perceptions of protection measures. As for respondents with moderate perceptions of protection measures, $43 \%$ of the variance in travel intention is explained by $\left(\beta_{2}=-0.54, \mathrm{P}<0.01\right)$ and travel anxiety $\left(\beta_{2}=-0.21, \mathrm{P}<0.05\right)$. This finding is in line with the UAE finding that when the belief of respondents of protection measures as adequate and efficient increases, the effect of travel fear and travel anxiety on their travel intention decreases. 


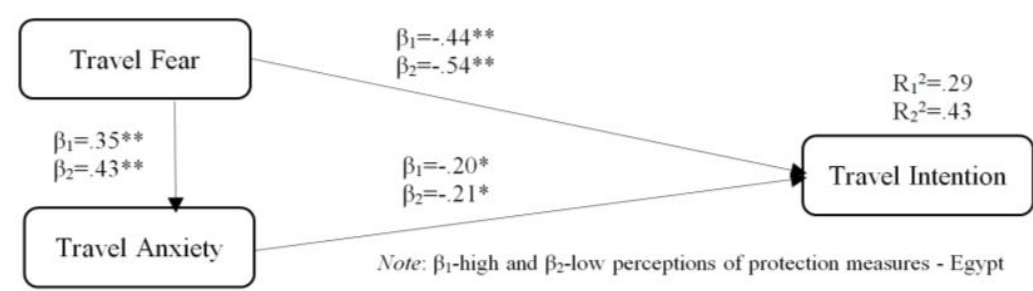

Figure 4. Perceptions of travel protection measures and travel intention for Egypt

\section{DISCUSSION}

The current study aimed to explore the travel intentions for tourism across two countries, the UAE and Egypt. Expectations have been presented around the world for restarting tourism despite the uncertainty of specific times of travel resume for tourism. With the roll-out of vaccination, there is a hope of a quick recovery of tourism. For the economic

concerns, countries replaced lockdown with strict travel measures including negative PCRs before travel and upon arrival, quarantine procedures, social distance and face mask instructions, and other safety measures. The current study investigated the effect of travel fear of COVID-19 and travel anxiety on travel intention for the year 2021. It used the protection measures as a moderator to examine how these measures could decrease an individual's fear and anxiety and increase the intention to travel for leisure. According to the findings of the current research, individuals are afraid of travel because of the COVID-19 infections and health concerns. This fear of travel increases their anxiety to take the risk of travel during the pandemic. The findings showed that both the respondents of the UAE and Egypt have similar perceptions of travel fear and travel anxiety. However, they have positive perceptions towards the protection measures adequacy and efficacy. These findings explain that people from different countries, cultures, gender and educational qualification are afraid to travel and take health risks while the pandemic continues and how health concerns hurt travel for tourism. This finding is in line with literature research (Turnšek et al., 2020; Zheng et al., 2021). Respondents are also anxious about travel during COVID-19. Anxiety is a consequence of fear where respondents feel worried, uncomfortable, and stressed during travel and therefore, this decreases their intention to travel. This finding is in line with previous studies of Reisinger and Mavondo (2005); Luo and Lam (2020); Wachyuni and Kusumaningrum (2020); Magano et al. (2021); Bratić et al. (2021).

Add to this, that anxiety increases as fear increases and respondents of the UAE and Egypt have expressed this relationship statistically and there is a positive causal association between fear of COVID-19 and travel anxiety. This finding is concurrent with previous research (i.e., Luo and Lam, 2020; Rodríguez-Hidalgo et al., 2020). With the strict precautions and protection measures taken by tourist destinations, individuals are carefully showing their intent to travel. Based on the categorization of respondents in this study of high perceptions of adequate and efficient protection measures, moderate and low perceptions, the fear, and anxiety of travel vary in their effect on their travel intentions. Findings revealed that when respondents have high perceptions of protection measures, the effect of travel fear and travel anxiety on their travel intention decreases compare to those respondents with moderate and low perceptions. This finding shows that when individuals perceive protection measures to be highly adequate and efficient and can protect them during travel, only $39 \%$ of their travel decision will be influenced by the negative impact of fear of travel and anxiety. When the perceptions move to be moderately adequate and efficient, $51 \%$ of individuals' travel decisions will be negatively affected by travel fear and anxiety. If the individuals do not perceive and believe in the adequacy and efficacy of protection measures, $71 \%$ of the negative effect on their travel intention will be due to their fear and anxiety. The protection measures are perceived by most respondents (with high and moderate perceptions) as effective, adequate, and they would be less likely to be infected if they strictly performed it.

The protection measures could help individuals to decrease their feelings of worry, the fear of losing their lives because of COVID-19 and decrease the negative impact of uncomfortable feelings if they think on travel in addition to reducing the negative effect of media on the impact of COVID-19. The feeling of fear is associated positively with the feeling of anxiety as shown in the findings of the present study, and therefore decreasing the fear feeling will reduce the anxiety feeling. The moderation effect of protection measures helps individuals to decrease the fear and anxiety of travel of COVID-19. The findings show that for the UAE respondents, the perceptions of protection measures decreased the negative influence of travel fear and anxiety from $71 \%$ (for respondents with low perceptions of protection measures) to $51 \%$ (for respondents of moderate perceptions) to $39 \%$ (for respondents of high perceptions of protection measures' adequacy and efficacy). The remarkable decrease of the negative effect of fear and anxiety reflects how important is the need of destinations to take strict travel protection measures and tourism services preventive measures to maintain travellers' safety. The case for the Egyptian respondents is similar as the protection measures perceptions have decreased the negative effect of travel fear and anxiety on travel intention from $43 \%$ (for moderate perceptions) to $29 \%$ (for high perceptions of protection measures).

\section{CONCLUSION}

The present study aimed to examine the relationship between travel fear and anxiety and intention to travel in the United Arab Emirates and Egypt. E-survey was adopted to collect data from respondents in the UAE and Egypt. Findings revealed that travel fear has a positive effect on travel anxiety, and both have a negative effect on the intention to travel in both countries, the UAE and Egypt. Travel intentions of respondents vary based on their perceptions of protection measures efficacy. Respondents with high perceptions of protection measures are more likely to take risks of travel while those with moderate and lower perceptions in protection measures' efficacy have limited intention to take risk and travel because of travel fear and anxiety of COVID-19.

\section{Implications}

The findings of the present study provide exploratory insights on travel intention during the COVID-19 pandemic. Theoretically, it tested the research model across two different countries, the UAE and Egypt. Although the UAE has taken serious measures to protect tourists and has a remarkable effort in vaccination of their citizens and residents compared to Egypt, respondents are still afraid and anxious about travel despite their positive intention to travel if they have a safe opportunity to do so. Furthermore, the study has provided important findings regarding the respondents' different perceptions towards protection measures in both the UAE and Egypt. It presented how the strict, adequate, and effective measures could decrease the negative effect of travel fear and anxiety on travel intention. Practically, the present study has provided some 
insights to travel and tourism stakeholders that individuals would like to travel if they have a safe opportunity. The findings have assured the importance of protection measures on decreasing the negative impact of fear and anxiety of travel and therefore, stakeholders must take strict protection measures to protect visitors and maintain their health concerns, from the one hand, in addition to their need to promote these measures to travellers to attract them and encourage their travel, on the other hand. Airlines, hotels, restaurants, tourism facilities (museums, parks, resorts, heritage sites, beaches, and other facilities) must introduce strict preventive measures to their visitors to support their activities resume and decrease the risk of infection, fear, and anxiety. In addition, destinations need to take strict, adequate, effective, and efficient procedures and measures to support the recovery of their tourism activities. Not only this, but they also need to promote these measures among the stakeholders, local people, and international travellers to decrease travel risk-taking. Stakeholders need also to have flexible procedures regarding bookings and cancellation policies to encourage travellers' restart for leisure purposes.

\section{Limitations and future research}

The present research has some limitations. First, it is based on a convenient sample and future studies should use multistage random samples to include many society categories. Also, the results of the current study are based on data collected between February and March 2021 and the perceptions towards travel could be changed according to the vaccination rates the decrease in the infection rates and the strict protection measures taken by countries. Furthermore, researchers should include more countries with different cultures to explore their perceptions of travel.

\section{REFERENCES}

Abou-Shouk, M., Zoair, N., \& Abdelhakim, A. (2019). Exploring the factors predicting M-commerce applications' adoption in tourism and hospitality: evidence from travel agencies, hotels and archaeological sites. Paper presented at the 9th Advances in Hospitality and Tourism Marketing and Management, Portsmouth, United Kingdom.

Ahorsu, D., Imani, V., Saffari, M., Griffiths, M., \& Pakpour, A. (2020). The Fear of COVID-19 Scale: Development and Initial Validation. International Journal of Mental Health and Addiction, 1-9. https://doi.org/10.1007/s11469-020-00270-8

Bratić, M., Radivojević, A., Stojiljković, N., Simović, O., Juvan, E., Lesjak, M., \& Podovšovnik, E. (2021). Should I stay or should I go? Tourists' COVID-19 risk perception and vacation behavior shift. Sustainability, 13(6): 3573. https://doi.org/10.3390/su13063573

Cohen, E., \& Cohen, s. (2012). Current sociological theories and issues in tourism. Annals of Tourism Research, 39(4), $2177-2202$. https://doi.org/10.1016/j.annals.2012.07.009

Hair, J., Howard, M., \& Nitzl, C. (2020). Assessing measurement model quality in PLS-SEM using confirmatory composite analysis. Journal of Business Research, 109: 101-110. https://doi.org/10.1016/j.jbusres.2019.11.069

Henseler, J., Ringle, C., \& Sarstedt, M. (2015). A new criterion for assessing discriminant validity in variance-based structural equation modeling. Journal of the Academy of Marketing Science, 43(1), 115-135. https://doi.org/10.1007/s11747-014-0403-8

Hullett, C., \& Witte, K. (2001). Predicting intercultural adaptation and isolation: Using the extended parallel process model to test anxiety/uncertainty management theory. International Journal of Interculture Relations, 25(2), 125-139. https://doi.org/10.1016/S0147-1767(00)00047-X

Joo, D., Xu, W., Lee, J., Lee, C.K., \& Woosnam, K.M. (2021). Residents' perceived risk, emotional solidarity, and support for tourism amidst the COVID-19 pandemic. Journal of Destination Marketing \& Management, 19: 100553. https://doi.org/10.1016/j.jdmm.2021.100553

Kock, N. (2020). WarpPLS User Manual: Version 7.0: ScriptWarp Systems.

Lee, B.K., Agarwal, S., \& Kim, H.J. (2012). Influences of travel constraints on the people with disabilities' intention to travel: An application of Seligman's helplessness theory. Tourism Management, 33(3): 569-579. https://doi.org/10.3390/ijerph17217859

Luo, J.M., \& Lam, C.F. (2020). Travel Anxiety, Risk Attitude and Travel Intentions towards "Travel Bubble" Destinations in Hong Kong: Effect of the Fear of COVID-19. International Journal of Environmental Research Public Health, 17(21), 7859. https://doi.org/10.3390/ijerph17217859

Magano, J., Vidal, D., Sousa, H., Dinis, M., \& Leite, A. (2021). Validation and Psychometric Properties of the Portuguese version of the Coronavirus Anxiety Scale (CAS) and Fear of COVID-19 Scale (FCV-19S) and Associations with Travel, Tourism and Hospitality. International Journal of Environmental Research and Public Health, 18(2): 427-439. https://doi.org/10.3390/ijerph18020427

McIntyre, N., \& Roggenbuck, J. (1988). Nature/person transactions during an outdoor adventure experience: A multi-phasic analysis. Journal of Leisure Research, 30(4): 4014-4022. https://doi.org/10.1080/00222216.1998.11949841

Perusini, J., \& Fanselow, M. (2015). Neurobehavioral perspectives on the distinction between fear and anxiety. Learning Memories, 22: 417-425. https://doi.org/10.1101/lm.039180.115

Reisinger, Y., \& Mavondo, F. (2005). Travel Anxiety and Intentions to Travel Internationally: Implications of Travel Risk Perception. Journal of Travel Research, 43(3): 212-225. https://doi.org/10.1177/0047287504272017

Rodríguez-Hidalgo, A.J., Pantaleón, Y., Dios, I., \& Falla, D. (2020). Fear of COVID-19, Stress, and Anxiety in University Undergraduate Students: A Predictive Model for Depression. Frontiers in Psychology, 11: 3041. https://doi.org/10.3389/fpsyg.2020.591797

Škare, M., Soriano, D.R., \& Porada-Rochoń, M. (2021). Impact of COVID-19 on the travel and tourism industry. Technological Forecasting and Social Change, 163: 120469. https://doi.org/10.1016/j.techfore.2020.120469

Soliman, M.S.A., \& Abou-Shouk, M.A. (2017). Predicting Behavioural Intention of International Tourists Towards Geotours. Geoheritage, 9(4): 505-517. https://doi.org/10.1007/s12371-016-0200-5

Turnšek, M., Gorenak, M., Brumen, B., Mekinc, J., Rangus, M., \& Štuhec, T. (2020). Perceived Threat of COVID-19 and Future Travel Avoidance: Results from an Early Convenient Sample in Slovenia. Academica Turistica - Tourism and Innovation Journal, 13(1), 319. https://doi.org/10.26493/2335-4194.13.3-19

Volo, S. (2021). The experience of emotion: Directions for tourism design. Annals of Tourism Research, 86, 103097. https://doi.org/10.1016/j.annals.2020.103097

Wachyuni, S., \& Kusumaningrum, D. (2020). The Effect of COVID-19 Pandemic: How are the Future Tourist Behavior?. Journal of Education, Society and Behavioural Science, 33: 67-76. https://doi.org/10.9734/jesbs/2020/v33i430219

Zenker, S., Braun, E., \& Gyimóthy, S. (2021). Too afraid to Travel? Development of a Pandemic (COVID-19) Anxiety Travel Scale (PATS). Tourism Management, 84: 104286. https://doi.org/10.1016/j.tourman.2021.104286

Zheng, D., Luo, Q., \& Ritchie, B.W. (2021). Afraid to travel after COVID-19? Self-protection, coping and resilience against pandemic 'travel fear'. Tourism Management, 83: 104261.https://doi.org/10.1016/j.tourman.2020.104261

*** OECD. (2020). Tourism Policy Responses to the coronavirus (COVID-19). Accessed: 25.05.2021, 13:35. https://www.oecd.org/ coronavirus/policy-responses/tourism-policy-responses-to-the-coronavirus-covid-19-6466aa20/\#boxsection-d1e31

*** UNWTO. (2020). Tourism and COVID-19: Priorities for Tourism Recovery - Global Guidelines. Accessed: 26.05.2021, 11:00. https://webunwto.s3.eu-west-1.amazonaws.com/s3fs-public/2020-05/UNWTO-Global-Guidelines-to-Restart-Tourism.pdf.

*** UNWTO. (2021). UNWTO World Tourism Barometer and Statistical Annex, January 2021. Accessed: 27.05.2021, 16:25. https://www.e-unwto.org/doi/pdf/10.18111/wtobarometereng.2021.19.1.1 